\title{
Remote-Controlled Experiment with Integrated Verification of Learning Outcome
}

\author{
Volker Staudt $^{\dagger}$, Stefan Menzner*, and Pavol Bauer** \\ $\dagger *$ Dept. of Electrical Eng. and Information Technology, Ruhr-University Bochum, Bochum, Germany \\ ** Dept. of Electrical Sustainable Energy, Delft University of Technology, Delft, The Netherlands
}

\begin{abstract}
Experiments in electrical engineering should mirror the key components of successful research and development: Understand the basic theory needed, test the resulting concepts by simulation and verify these, finally, in the experiment. For optimal learning outcome continuous monitoring of the progress of each individual student is necessary, immediately repeating those subjects which have not been learned successfully. Classically, this is the task of the teacher. In case of remote-controlled experiments this monitoring process and the repetition of subjects should be automated for optimal learning outcome. This paper describes a remote-controlled experiment combining theory, simulation and the experiment itself with an automated monitoring process. Only the evaluation of the experimental results and their comparison to the simulation results has to be checked by a teacher. This paper describes the details of the educational structure for a remote-controlled experiment introducing active filtering of harmonics. For better understanding the content of the learning material (theory and simulation) as well as the results of the experiment and the underlying booking system are shortly presented.
\end{abstract}

Key Words: Education methodology, Education tool, Online experiment, Power Quality, Active filter, Harmonics

\section{INTRODUCTION}

In electrical engineering the process of solving a problem usually starts with theoretical considerations. The results of these considerations lead to concepts which are tested by simulation. Promising simulation results are implemented into an experiment verifying the simulation and giving additional information for final implementation. Universities implement this process in experiments for students.

The variety of experiments which can be implemented at one single university is limited. Especially large, close-topractice power electronics experiments, in this case a Shunt Active Filter experiment with a rated power of about $20 \mathrm{kVA}$, cannot be operated at each university. Additionally, due to the speed of technical development, active engineers (with a lot of practical experience) have to update their knowledge continuously. This is often referred to as "life-long learning". Both demands can be satisfied by a distance-learning version of such an experiment: It extends the choice for students and enables life-long learning for active engineers [1], [2]. The learning material for the experiment presented here is designed such that it meets the demands of students and active engineers equally well.

\footnotetext{
Manuscript received May 17, 2010; revised Aug. 4, 2010

† Corresponding Author: staudt@eele.rub.de

Tel: +49-234-322-3962, Fax: +49-234-32-0396, Ruhr-Univ. Bochum

* Dept. of Electrical Eng. and Information Technology, Ruhr-University Bochum, Germany

** Dept. of Electrical Sustainable Energy, Delft University of Technology, The Netherlands
}

Of course an on-line experiment cannot replace real-life experiments. Nevertheless it provides an interesting complement. Several requirements have to be met by such an on-line experiment:

- The learning material has to be designed so that the learning outcome is guaranteed, even if the experiment is used with minimal or even without the assistance of a teacher

- Theory, simulation and experiment have to interact

- The on-line version must be as close as possible to the look-and-feel of a real experiment

- Using simulation and experiment must be simple

This paper describes an on-line experiment which mirrors the usual workflow in research and development of power electronics applications and meets the demands stated above. The learning material starts with introducing a model and its theoretical background. Next, errors deliberately included into a given simulation structure have to be found and eliminated. Finally the concepts learned are verified on a real test bench - whose control and measurements are available on-line. The learning material is designed such that the learning outcome is continuously monitored and verified by mandatory questions, also checking adequate use of the simulation tool. In the end the students are asked to write a report. In this the students should, among other tasks, comment on differences between simulation and measurement. This report, however, still has to be evaluated by a teacher - an automatic evaluation is not possible at the moment.

The continuous monitoring of the learning outcome is partly 


\begin{tabular}{|c|c|c|c|c|c|}
\hline theory & $\begin{array}{l}\text { exercise \& } \\
\text { verification }\end{array}$ & k simulation & $\begin{array}{l}\text { exercise \& } \\
\text { verification }\end{array}$ & experiment & report \\
\hline
\end{tabular}

Fig. 1. Simplified structural diagram of the verification of the learning outcome.

based on the use of passwords, partly uses the options of Adobe $\AA$ Presenter $\AA$ to integrate short exams into a Power

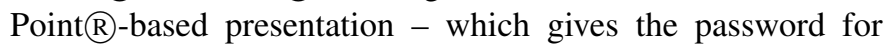
the next step in the learning process on its final slide.

\section{BASIC EDUCATIONAL STRUCTURE}

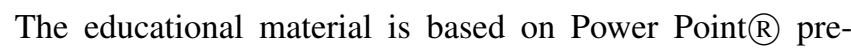
sentations. These include many written comments which are visible in the available hand out. Adobe $(R$ Presenter $(R$ web

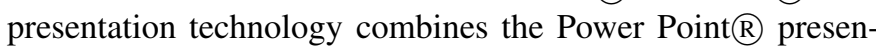
tation with speech and animation. The animations are triggered in perfect match to the recorded voice. Mandatory questions are included - which direct to a selected slide in case of a wrong answer. In this way immediate feedback is given and the associated section of theory is repeated. In parallel to the presentation itself the student can refer to the hand out.

Only successfully finishing a presentation reveals a password for the next presentation or, finally, the experiment.

An example for this monitoring process in combination with theory and simulation is the following: The students have to perform calculations based on the theory conveyed by the learning material. The results give parameters for some elements included into the simulation. The students run the simulation with their parameters and note the simulation results. Correct results are verified by questions about these results asked in the Adobe $\mathrm{R}$ Presenter $\mathrm{R}$ web presentation. In this way after each main aspect the learning outcome is verified by questions to the students. The basic idea of this approach is shown in Fig. 1.

A further feature of the experiment is its scalability: Two versions of the experiment exist:

- a basic version introducing stationary operation

- an advanced version treating control aspects and introducing dynamic behavior

For the advanced version additional learning material has to be worked through, revealing a special password for the experiment. Offering these two versions of the experiment has two advantages: On the one hand two levels of complexity allow the adaption of the experiment to the knowledge and ability of the students and the level of the course they are in. The experiment could be used in Bachelor and Master courses. On the other hand the possibility to gain access to the advanced version - whose possibilities are visible also in the web controls of the basic version, but grayed out will motivate the students to continue. Perhaps even past the demands of their course.

The structure described up to now covers the first two demands given in the introduction: Verification of learning outcome and a close link between theory, simulation and experiment. To explain how the two demands concentrating on the look-and-feel and on the usability of the experiment are met a more detailed introduction of the experiment itself and the associated web pages is needed. These aspects should not be disregarded: If the students spend much time on learning how to operate simulation and experiment or have problems to include their results into text processing software, the value of the experiment as a whole is reduced considerably.

Therefore, after explaining the experiment itself, example figures directly taken from simulation and on-line experiment illustrate in which way the experiment is operated and how the results can be viewed - and in turn analyzed and commented - by the students. All figures can easily be copied and pasted into text-processing software to allow the creation of a final report. Those figures in this paper which present simulation results and measurement results have directly been imported from the web page output.

Only the final report is checked by a teacher who gives the feedback - and a perhaps a mark - to the students.

It is important to note that the comparison of simulation results and experimental results is one of the tasks given to the students for the final report. In this way the students understand possibilities and limitations of theory and simulation.

\section{Structure OF THE EXPERIMENT}

The experiment consists of a load section and a parallel compensator (shunt active filter) [3], see the structural diagram given in Fig. 2. The load section contains a grid-commutated thyristor converter with capacitive smoothing and resistive load and an induction machine without load (for reactive current generation). The compensator section consists of an IGBT converter, rated at about $20 \mathrm{~kW}$, and its control. The IGBT converter is coupled to the internal point of connection (IPC) by a T-type LCL filter. Fig. 3 gives the simplified structural diagram as it is displayed on the web page of the experiment. It shows the main components and the names and reference directions of the measured quantities.

For calculations and graphic understanding the structure displayed in Fig. 2 is far too complex. Therefore the learning material deduces a simplified structure dedicated to calculating frequency components of compensator voltage and associated compensator current. Such compensator currents are then used to compensate undesired load current components. The equivalent circuit resulting from this simplification is shown in Fig. 4. In this way the students do not only learn how to calculate compensator current components but also that purposeful simplifications are important for understanding and calculating.

The simplified equivalent scheme for calculating compensator current harmonics shown in Fig. 4 is based on space vectors (marked by the arrow as underscript). These are shortly introduced in the learning material. The students use this equivalent scheme in combination with a simulation to verify that they really understand how the compensator works. This is detailed in the next section.

\section{COMPENSATION OF SEQUENCE COMPONENTS: SIMULATION}

The shunt active filter used in the experiment is designed to provide reactive power compensation and compensation of 


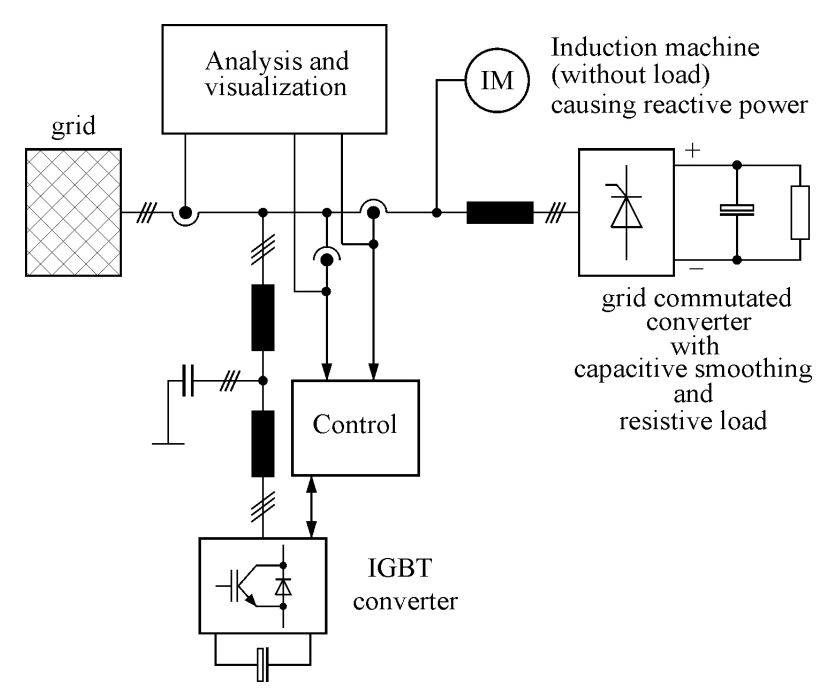

Fig. 2. Structural diagram of the experiment.

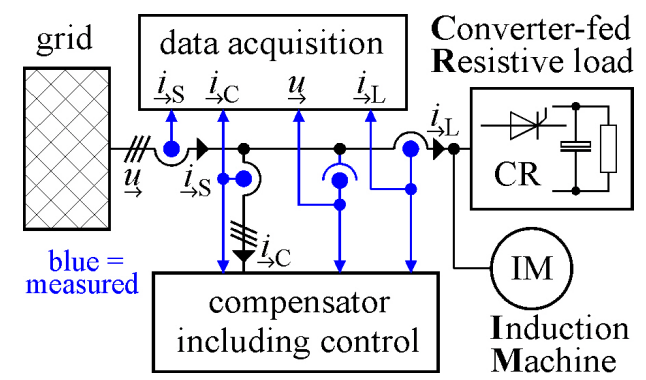

Fig. 3. Simplified structural diagram of the experiment as used on the web page.

selected low-order harmonics with minimal effort [4], [5]. Minimal effort means minimal voltage and current rating of the converter and minimal calculation power of the closed-loop compensator control.

In load currents, usually only certain sets of harmonics with certain sequence characteristics have considerable amplitude. These are $+1, \sim 1, \sim 5,+7, \sim 11,+13$, e.g., where "+" refers to positive sequence and " $"$ to negative sequence. The control of the filter detects and eliminates only these selected sets of harmonic sequence components (except +1 active, the desired set of currents), giving improved but non-optimal currents [6].

Generating current sequence components using a selfcommutated DC-link converter such that the respective load current sequence component is eliminated is explained in this on-line experiment and its learning material.

\section{MODEl OF THE DC-LINK CONVERTER AND SIMULATION}

A simple but effective model of the DC-link converter connected in parallel to the load is given by a controllable voltage source with series inductance, Fig. 3. This model applies to all similar grid-connected converters and is therefore very important to be understood. The load is, here, modeled as a current source.

A further simplification results from neglecting possible harmonics of the source (grid) voltage. The equivalent scheme for calculating the compensator current is reduced to the one

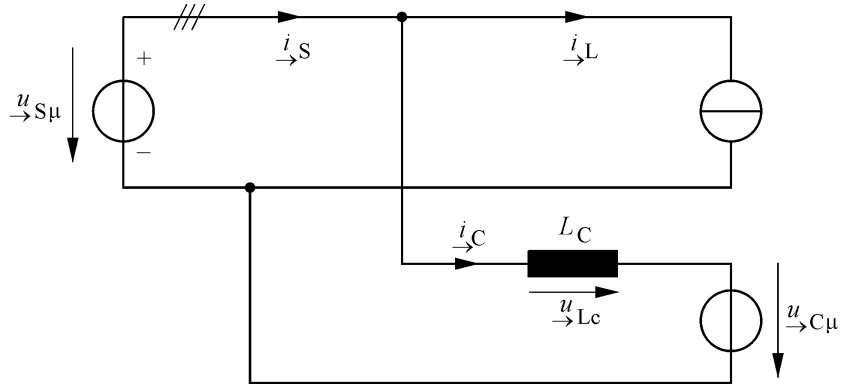

Fig. 4. Simplified equivalent circuit of the experiment.

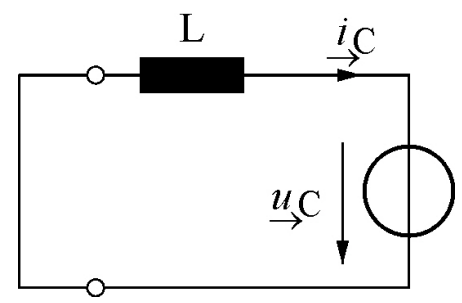

Fig. 5. Structural Reduced equivalent scheme for compensator current calculation.

seen in Fig. 5. The compensator current can now be derived based on (1), taking into account that depending on the kind of sequence (positive or negative) the voltage space vector has to be rotated by $+90^{\circ}$ or $\sim 90^{\circ}$ respectively, as explained by Fig. 6.

Some questions concerning this theory are asked in the presentation. The students have to prove their ability to really work with the theory in combination with a simulation, see next subsection.

\section{Simulation AND SEQUENCE COMPONENT COMPENSATION}

The freeware viewer of Caspoc $R$ [7] is used for simulation. The structure of the simulation is provided within the learning material. The students now run the simulation which includes a block for measuring the magnitude of harmonic sequence components of the source current. The resulting voltage and current waveform can be seen in Fig. 7. For the sequence component of order $\sim 5$ (fifth negative sequence) current magnitude and phase are given in Fig. 8 as read-out of the associated block of the simulation structure.

Based on these readings and the concept learned the students calculate the compensator voltage needed to compensate this sequence component. They insert the derived parameters into the simulation and run it again. The magnitude is now reduced considerably (but not to zero due to small non-idealities of the simulation). This has to be done for one positive and one negative sequence component to check if the concept of rotation (Fig. 6) is understood. The values of the remaining magnitude have to be entered into the Presenter $R$ presentation, only allowing the students to continue with correct values (Fig. 1).

In this way the simulation gives two advantages: On the one hand the students learn how a model is built, simplified further and used together with a simulation. On the other hand it allows the verification of the learning outcome, because the 

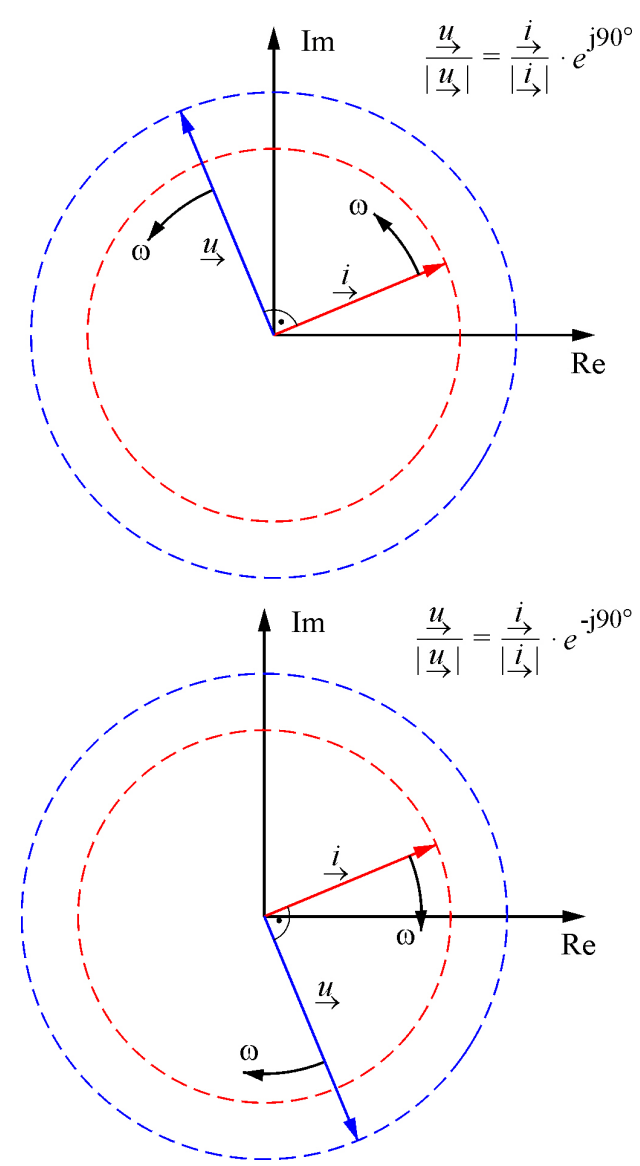

Fig. 6. Voltage and current space vector at an inductor: positive and negative sense of rotation.

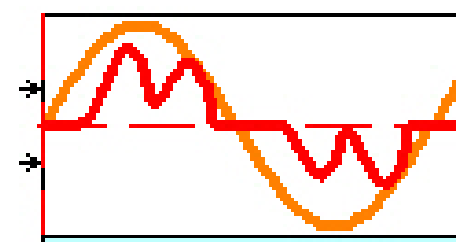

Fig. 7. Simulation: Voltage and current (one of three phases).

results of a simulation are - in contrast to experimental results - largely deterministic.

\section{AUTOMATIC COMPENSATION AND TROUBLESHOOTING}

Having completed this first simulation exercise a second simulation uses a set of controllers to automatically compensate harmonic sequence components (Fig. 9). The simulation deliberately contains incorrectly set parameters which lead to unexpected compensation results (Fig. 10). The students have to find the correct parameters and insert them into the simulation. Fig. 9, e.g., shows the given and the correct selection of the sequence components to be compensated.

The students have to find the errors, correct them and run the simulation again. The combination of time-domain and frequency-domain representation helps to localize the errors. The Presenter $\mathrm{R}$ presentation asks for details verifying that this task has been understood and completed. Having successfully corrected the parameters, time-domain and frequency-domain

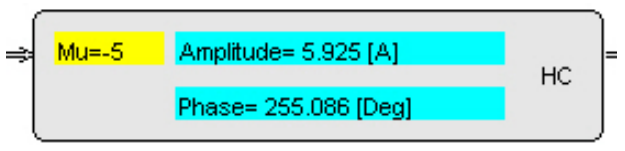

Fig. 8. Sequence component analysis block of the simulation with read-out for -5 th component.

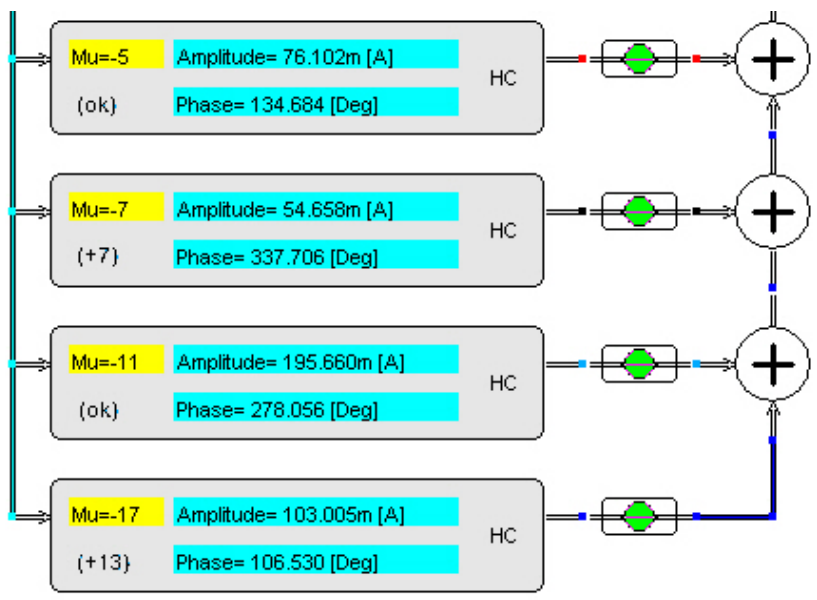

Fig. 9. Simulation: Control blocks for elimination of four sequence components

representation clearly prove that the compensation now works correctly (Fig. 11).

In addition the students can test the effect of switching on or off any of the controller outputs, increasing understanding and verifying that these sequence components can really be compensated independently.

With these tasks completed the students may already access the basic version (stationary) of the on-line experiment (Fig. 12). For advanced students, and to increase motivation, the learning material and the experiment offer an advanced version introducing control and dynamics described in the next section.

In the basic version the controls for the advanced version are visible but grayed out. In this way the students are motivated to unlock the additional features by continuing with the learning material

\section{STRUCTURE OF THE CONTROL AND DYNAMIC COMPENSATION}

For advanced students (or those who want to try) an advanced version is proposed - in this way increasing the motivation to continue. Here the structure of the control (in rotating coordinates) already used as a "black box" in the previous section is introduced (Fig. 13).

On the left-hand side the source-current space vector enters the controller. It is transformed into rotating coordinates, turning the selected harmonic system into a DC component. The sliding integration eliminates all harmonics but not the DC portion; interharmonics are damped but cannot be eliminated completely. The result is the complex Fourier Series coefficient of the source current of harmonic system $\mu$.

An I-type controller and a $90^{\circ}$-rotation give the voltage space vector needed to force the compensation current with regard to the total inductance of the T-type filter dominating 


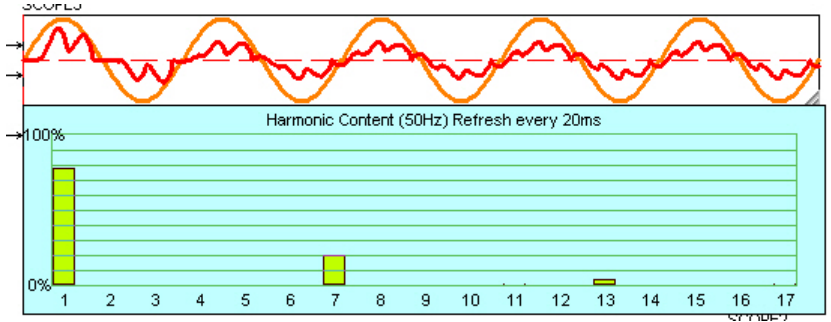

Fig. 10. Simulation result (time and frequency domain), initial settings (errors to be found).

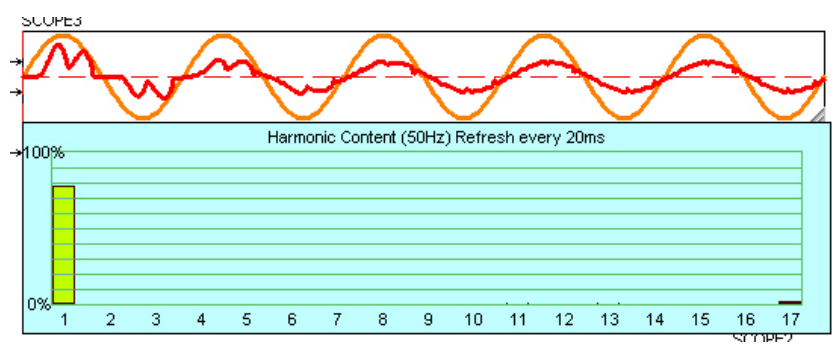

Fig. 11. Simulation result (time and frequency domain), errors found and corrected by students.

in the compensation-frequency range. This result is still in rotating coordinates. A back-transformation into original coordinates gives the associated voltage space vector in original coordinates, which is then one part of the voltage set-point value of the compensator. Due to the I-type controller, the source-current harmonic is eliminated completely if no sourcevoltage harmonic of the same frequency exists.

One such controller is used for each harmonic sequence component to be eliminated. The output signals of all these controllers are summed up to give the set-point value of the compensator voltage, Fig. 9.

\section{THE ON-LINE EXPERIMENT}

The experiment itself is controlled by a web page which can be used by any usual web browser (Fig. 12). It offers control of the loads and the compensator and allows to perform and to analyze measurements. By comparing simulation and measurement the students learn that the main effects are described correctly by the simulation. However, side effects have not been included into the model and are therefore not present in the simulation. One of these side effects is, e.g., grid-voltage distortion. A second one are parasitic properties of elements, e.g., the resistive component of an inductor.

The source current without compensation is shown in Fig. 14 (corresponding to the simulation result shown in Fig. 7). With compensation, the source current becomes much more sinusoidal (Fig. 15, corresponding to Fig. 11). These results can also be viewed in frequency domain (Fig. 16 corresponding to the lower part of Fig. 11). To show the effect of compensation source current and load current harmonics are displayed. Each set of lines belongs to one frequency (one harmonic order). The amplitude of the fundamental frequency component is reduced because the reactive current component is compensated.

The display options on the web page controlling the experiment allow to include source current, load current, compen-

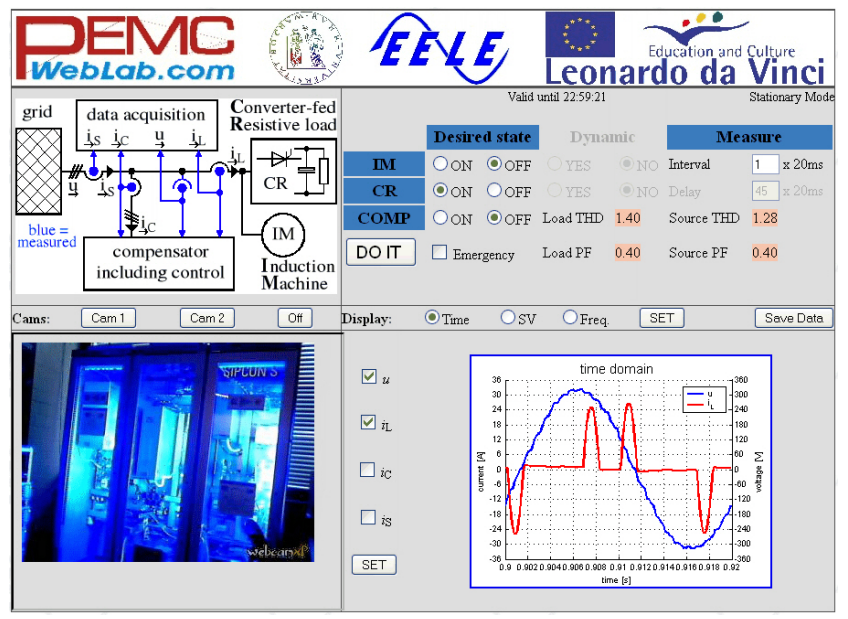

Fig. 12. Web page controlling the experiment (basic). Controls for advanced version grayed out.

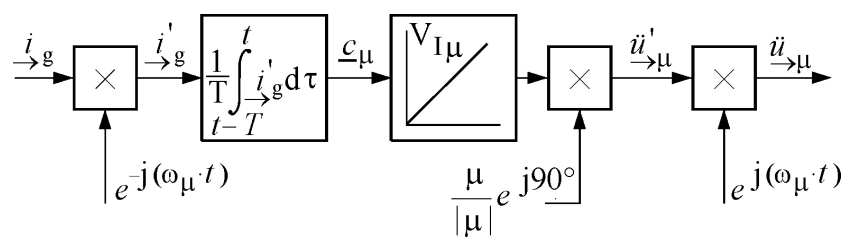

Fig. 13. Structure: Control for harmonic sequence-component elimination

sator current and IPC voltage harmonics into the same figure.

In addition the simulation results can be displayed as spacevector track curves. In this way the experiment also allows a deeper insight into the use of the space-vector transformation, for example viewing the dynamic currents when switching on the induction motor of the experiment.

\section{TECHNICAL ASPECTS}

Fig. 17 gives the structure of the internet-based control of the experiment.

The students book and first connect to the web server on the PC of the experiment using a Booking System configured by the University of Maribor, calling a PHP script. It first asks for the password, determining the mode (stationary or

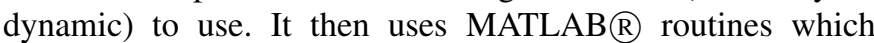
in turn call $\mathrm{C}$-code-based functions to access the experiment itself and make measurements. The measured values are processed by MATLAB $R$, returning figures displayed by the PHP Script. Besides a usual web browser accepting cookies for the session and the freeware version of the CASPOC $\mathrm{R}$ simulator no software needs to be available or installed on the computers of the students. Analysis of measurements and display functions are seamlessly integrated into the experiment generating platform-independent graphics. In this way results can easily be transferred into text processing software on any platform.

\section{CONClusions}

The paper presents the innovative educational structure of a remote-controlled experiment. The students are guided through a combination of theory, simulation and experiment by 


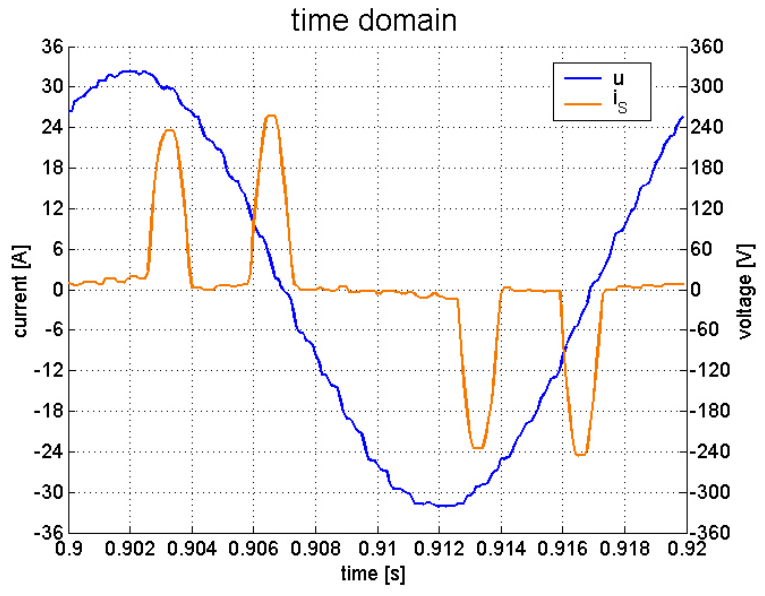

Fig. 14. Voltage at IPC and source current without compensation.

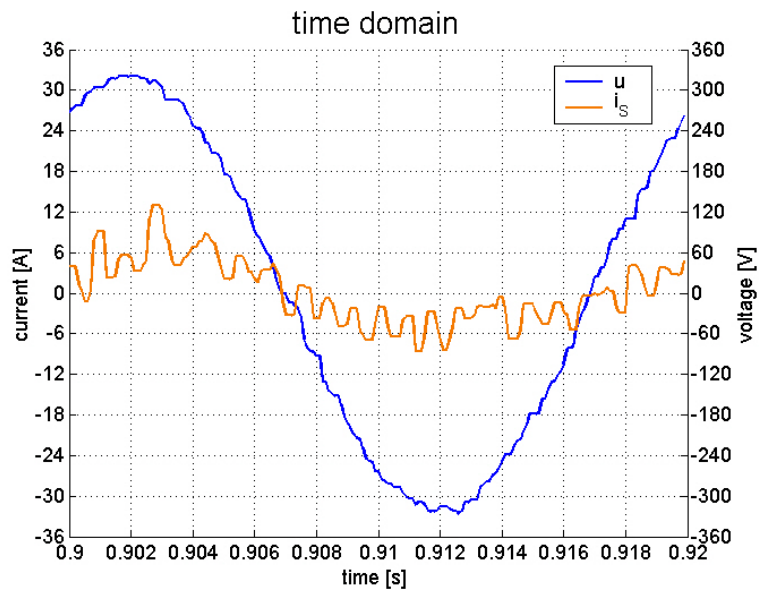

Fig. 15. Voltage at IPC and source current with compensation.

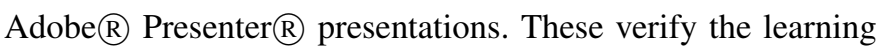
outcome step by step asking mandatory questions and revealing passwords for the next step only if successfully completed.

Questions about simulation results which base on successfully applied theoretical concepts link simulation and theory. They verify the understanding of the basic theoretical concepts as well as the correct use of the simulation. In this way the students effectively learn and understand a new subject with minimal control effort of a teacher.

Theory, simulation and experiment are available in a basic and an advanced version. In this way different levels of complexity can be chosen and at the same time the motivation for students to continue is increased.

Writing a report based on simulation results and experimental results is supported by the option to copy results into text processing software without need for additional tools. In the end, only the final reports written by the students have to be checked and rated by a teacher.

\section{ACKNOWLEDGMENT}

This work has been performed within the project "Elearning Distance Interactive Practical Education (EDIPE)", The project was supported by the European Community within

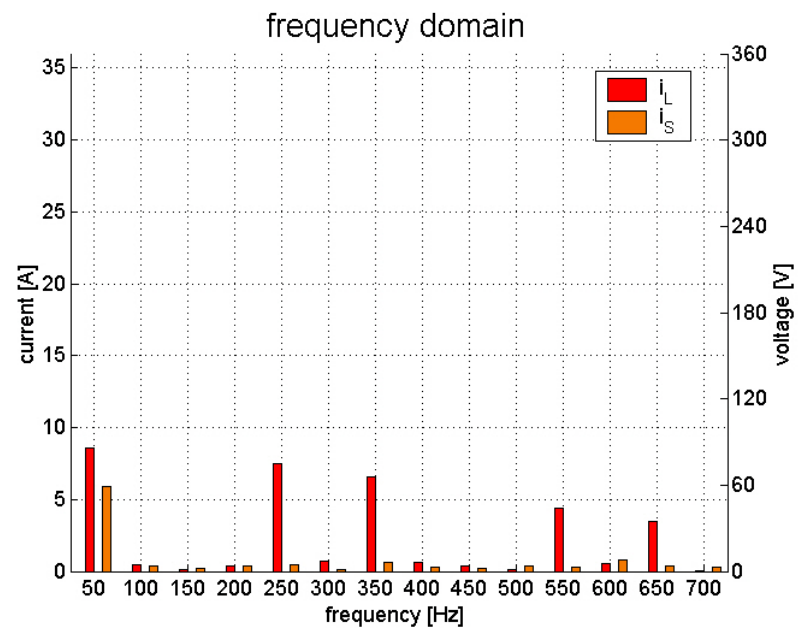

Fig. 16. Source current with compensation and load current, frequency domain representation; each set of lines belongs to one frequency, e.g., the first two lines to $50 \mathrm{~Hz}$.

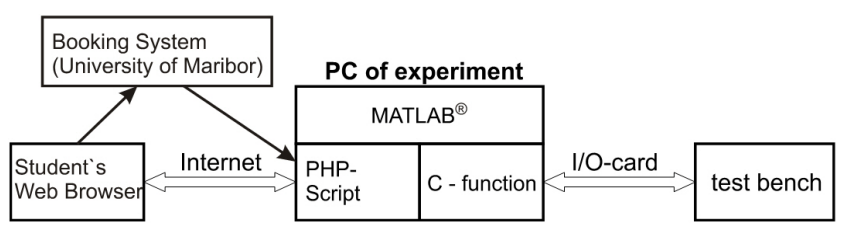

Fig. 17. Structure of the internet-based control of the experiment.

framework of Leonardo da Vinci II programme (project No CZ/06/B/F/PP-168022). The opinions expressed by the authors do not necessarily reflect the position of the European Community, nor does it involve any responsibility on its part.

\section{REFERENCES}

[1] P. Bauer, D. Maga, J. Sitar, J. Dudak, R. Hartansky, "PEMCWebLab Distance practical education for power electronics and electrical drives,' 38th Annual IEEE Power Electronics Specialists Conference Power Electronics Education Workshop (PEEW07), 2007.

[2] P. Bauer, V. Staudt, "Remote controlled practical education for Power Electronics," 12th European Conference on Power Electronics and Applications, 2007.

[3] P. Bauer, V. Hájek, V. Staudt, A. Steimel, "Power quality and active filters as web-controlled experiment in the frame of PEMC WebLab," EPE-PEMC 2008, S.2402 - 2408, 2008.

[4] M. Sonnenschein, M. Weinhold, "Comparison of time-domain and frequency-domain control schemes for shunt active filters," ETEP, Vol. 9, No. 1, pp.5-16, 1999.

[5] M. Sonnenschein, M. Weinhold, R. Zurowski, "Shunt-Connected Power Conditioner for Improvement of Power Quality in Distribution Networks," 7th International Conference on Harmonics and Quality of Power (ICHQP VII), pp. 27 - 32, 1996.

[6] M. Depenbrock, V. Staudt, "The FBD-Method as tool for compensating total non-active currents," 8th International Conference on Harmonics and Quality of Power (ICHQP VIII), pp.320 - 324, Oct. 1998.

[7] www.caspoc.com; www.simulation-research.com

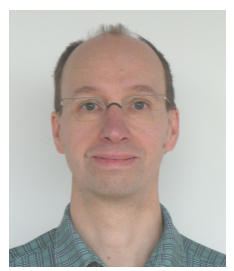

Volker Staudt was born in Bochum, Germany, in 1962. He received the diploma degree in electrical engineering in 1986 and the doctoral (Ph.D.) degree in electrical engineering in 1993, both from the RuhrUniversity Bochum, Bochum, Germany. He finished his habilitation in 2000 on the subject of power definitions and compensation strategies and was awarded the title of a professor in 2009. Since 1987, he is with the Department of Electrical Power Engineering and Power Electronics, Faculty of Electrical Engineering and Information Technology, 
Ruhr-University Bochum. His research interests are in the areas of power electronics, control of ac machines, power definitions and compensation strategies. Prof. Staudt is member of the VDE and senior member of the IEEE.

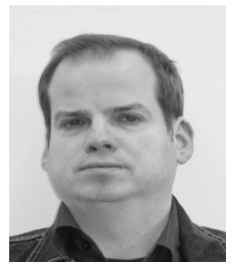

Stefan Menzner was born in Recklinghausen, Germany, in 1972. He received the diploma degree in electrical engineering in 2005 from the Ruhr-University Bochum, Bochum, Germany. Since 2005, he is with the Department of Electrical Power Engineering and Power Electronics, Faculty of Electrical Engineering and Information Technology, Ruhr-University Bochum, as research assistant. His research interests are in the areas of resonant converters, measurement-based analysis of power-electronics devices and microcontroller-based control and filtering.

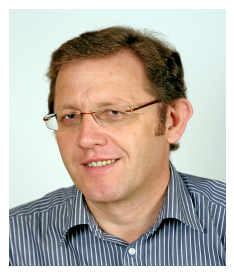

Pavol Bauer received his Masters in Electrical Engineering at the Technical University of Kosice ('85), Ph.D. from Delft University of Technology ('95) and title prof. from the president of Czech Republic at the Brno University of Technology (2008). Since 1990 he is with Delft University of Technology, teaching Power electronics and Electrical Drives. From 2002 to 2003 he was working partially at KEMA (Arnhem) on different projects related to power electronics applications in power systems. P. Bauer published over 50 journal and 200 conference papers in his field, he is an author or co-author of 6 books, he holds international patent and organized several tutorials at the international conferences. He has worked on many projects for industry concerning wind power, power electronic applications for power systems such as Smarttrafo etc. and participated in several Leonardo da Vinci EU projects as project partner (ELINA, INETELE) and coordinator (PEMCWebLab.com). He is a Senior Member of the IEEE, Chairman of Benelux IEEE Joint Industry Applications Society, Power Electronics and Power Engineering Society chapter, member of the EPE-PEMC council, EPE member and also member of international steering committee at numerous conferences. 